Article

\title{
Methodological Proposal for Automated Detection of the Wildland-Urban Interface: Application to the Metropolitan Regions of Madrid and Barcelona
}

\author{
Andrea Zambrano-Ballesteros ${ }^{1}$, Sabina Florina Nanu ${ }^{1, *}$, José Tomás Navarro-Carrión ${ }^{2}$ \\ and Alfredo Ramón-Morte ${ }^{3}$ (D) \\ 1 Instituto Interuniversitario de Geografía, Universidad de Alicante, 03690 San Vicente del Raspeig, Spain; \\ azb10@alu.ua.es \\ 2 Laboratorio de Geomática, Instituto Interuniversitario de Geografía, Universidad de Alicante, \\ 03690 San Vicente del Raspeig, Spain; jt.navarro@ua.es \\ 3 Departamento de Análisis Geográfico Regional y Geografía Física, Universidad de Alicante, \\ 03690 San Vicente del Raspeig, Spain; alfredo.ramon@ua.es \\ * Correspondence: sfn5@alu.ua.es
}

\section{check for} updates

Citation: Zambrano-Ballesteros, A.; Nanu, S.F.; Navarro-Carrión, J.T.; Ramón-Morte, A. Methodological Proposal for Automated Detection of the Wildland-Urban Interface: Application to the Metropolitan Regions of Madrid and Barcelona ISPRS Int. J. Geo-Inf. 2021, 10, 381. https://doi.org/10.3390/ijgi10060381

Academic Editors: Claudio Vanneschi and Wolfgang Kainz

Received: 21 April 2021

Accepted: 27 May 2021

Published: 3 June 2021

Publisher's Note: MDPI stays neutral with regard to jurisdictional claims in published maps and institutional affiliations.

Copyright: (c) 2021 by the authors. Licensee MDPI, Basel, Switzerland. This article is an open access article distributed under the terms and conditions of the Creative Commons Attribution (CC BY) license (https:// creativecommons.org/licenses/by/ $4.0 /)$
Abstract: Official information on Land Use Land Cover is essential for mapping wildland-urban interface (WUI) zones. However, these resources do not always provide the geometrical or thematic accuracy required to delimit buildings that are easily exposed to risk of wildfire at the appropriate scale. This research shows that the integration of active remote sensing and official Land Use Land Cover (LULC) databases, such as the Spanish Land Use Land Cover information system (SIOSE) creates the synergy capable of achieving this. An automated method was developed to detect WUI zones by the massive geoprocessing of data from official and open repositories of the Spanish national plan for territory observation (PNOT) of the Spanish national geographic institute (IGN), and it was tested in the most important metropolitan zones in Spain: Barcelona and Madrid. The processing of trillions of LiDAR data and their integration with thousands of SIOSE polygons were managed in a Linux environment, with libraries for geographic processing and a PostgreSQL database server. All this allowed the buildings that are exposed to wildfire risk with a high level of accuracy to be obtained with a methodology that can be applied anywhere in the Spanish territory.

Keywords: GIS; LiDAR; PostGIS; wildland-urban interface (WUI); wildfire; SIOSE; geo open data; geo small data

\section{Introduction}

Despite the scientific and technological developments in recent years, there are still natural phenomena that cause loss of human lives and high socio-economic costs in the context of climate change that may increase their severity and frequency. Forest fires, endemic in zones with a Mediterranean climate, together with certain human activities, generate landscape degradation, a barely remediable transformation in the environment, and environmental changes, such as soil erosion or decreasing air quality [1]. Wildfires take place every year in Spain due to climate conditions, such as the long summer period, combined with low rainfall and high temperatures. These factors affect forest vegetation and facilitate wildfire outbreak and spread. Furthermore, there are anthropogenic causes [2]; $95 \%$ of the fires that occur in the Mediterranean region are produced by human causes, either by accidents, negligence, intentional acts, etc. [3]

Climate change and changes in land use affect the fire regime [4]. In the touristic zones and in the metropolitan environments where settlements are in contact with forest zones, this problem is more severe, for obvious reasons, which increase the real state and human exposure to fire risk. In addition, there is an increase in density in these zones due to the proximity of human activities to the forest zone and an increase in the vulnerability of 
forest vegetation produced by the abandonment of traditional agricultural activities in the peri-urban environments of large cities and holiday dwellings. The expansion of these WUI zones in the United States was very significant [5] and it has substantially increased the cost of wildfire suppression and the treatment of forest fuels, not to mention the damage that they cause [6]. This is also the situation in Spain [7] and has led to detailed studies on its legal regulation in Europe and in Spain, considering the changes in the LULC data and the increased vulnerability that this creates [8].

The coexistence between forest areas and new settlements, with non-traditional activities in the rural environment, is one of the main characteristics of the concept of the wildland-urban interface (WUI), which is defined in the Spanish forest law (Ley de Montes) $43 / 2003$ as those areas that include housing estates, other buildings, works, electrical installations and transport infrastructures located in or near forest land, that can entail a fire hazard or be affected by them. Royal Decree 893/2013 provides another description of this concept, defining it as zones where buildings meet forest land.

There are particularly good works that delimit the areas in which this urban and forest contact occurs, identifying the typology and the degree of hazard [9], and indeed the recent evolution of the landscape in many Mediterranean countries is conditioned by the growth in urbanized zones. The expansion of WUI zones in Spain exceeds one million hectares (about $4 \%$ of the total forest surface), with an average of 12,500 forest fires per year during the past ten years [7], gaining prominence in the metropolitan environments of Madrid and Barcelona and in the Mediterranean coast [10], where urbanizers seek single-family dwellings or second homes, attracted by the aesthetic appeal of a natural environment, which causes a situation that alters the traditional landscape and brings a social and cultural behavior that is alien to that environment and is of danger of a wildfire [8]. Therefore, it is very important to identify automated methods that help us to delimit this type of WUI zone at different scales and, in this case, the most important metropolitan zones in Spain.

This study is a continuation of a research line initiated in the SIOSE-INNOVA project (subprogram "Retos I + D + I 2016" for 2016 R + D + i challenges, Spanish Ministry of Economy and Competitiveness, CSO2016-79420-RAEI/FEDER UE) in which the exploitation of Geo Open Data repositories of the Spanish national plan for territory observation (PNOT) were tested to obtain the delimitation of these WUI zones in an automated manner for large areas and with a high level of detail. For this purpose, a methodology based on the use of free software tools and standard open data is proposed for testing in the automated detection of WUI zones in the periphery of the metropolitan areas of Madrid and Barcelona (Figure 1).

Technological developments in remote sensing and in the geographic information process have led to the generation of highly detailed data that are of great use in the study of wildfires in WUI zones [11]. In this respect, the use of Airborne Laser Scanning (ALS), also known as LiDAR technology, is noteworthy for determining the density of forest fuel, measuring hazard and mapping wildfire risk in settlements, [12] as well as for generating models for the automated identification of firefighter safety zones [13]. LiDAR data and aerial photographs were used to determine the volume of forest masses, land slope or flame height. Some methodologies using laser information as fundamental data were developed to model fire behavior during a wildfire [14].

There are good examples of the delimitation of WUI zones using ALS echoes in Spain, such as the analysis carried out by Badia A. and Gisbert, M. [11] at an experimental level in the metropolitan area of Barcelona, although limited to a very specific area. In Galicia, Robles et al. [15] successfully obtained the exposure of settlements to wildfire risk through non-automated analysis of LiDAR data, or by using decision trees and Geographic Information Systems (GIS), as in the case of Fernández-Álvarez, M. et al. [16]. Initial research in the SIOSE-INNOVA project for the delimitation of WUI zones began with the use of PNOT LiDAR in Valle del Tiétar (Segovia) and in Camp del Turia (Valencia), through active remote sensing of zones where vegetation and buildings were in close proximity to each other [17-19]. 


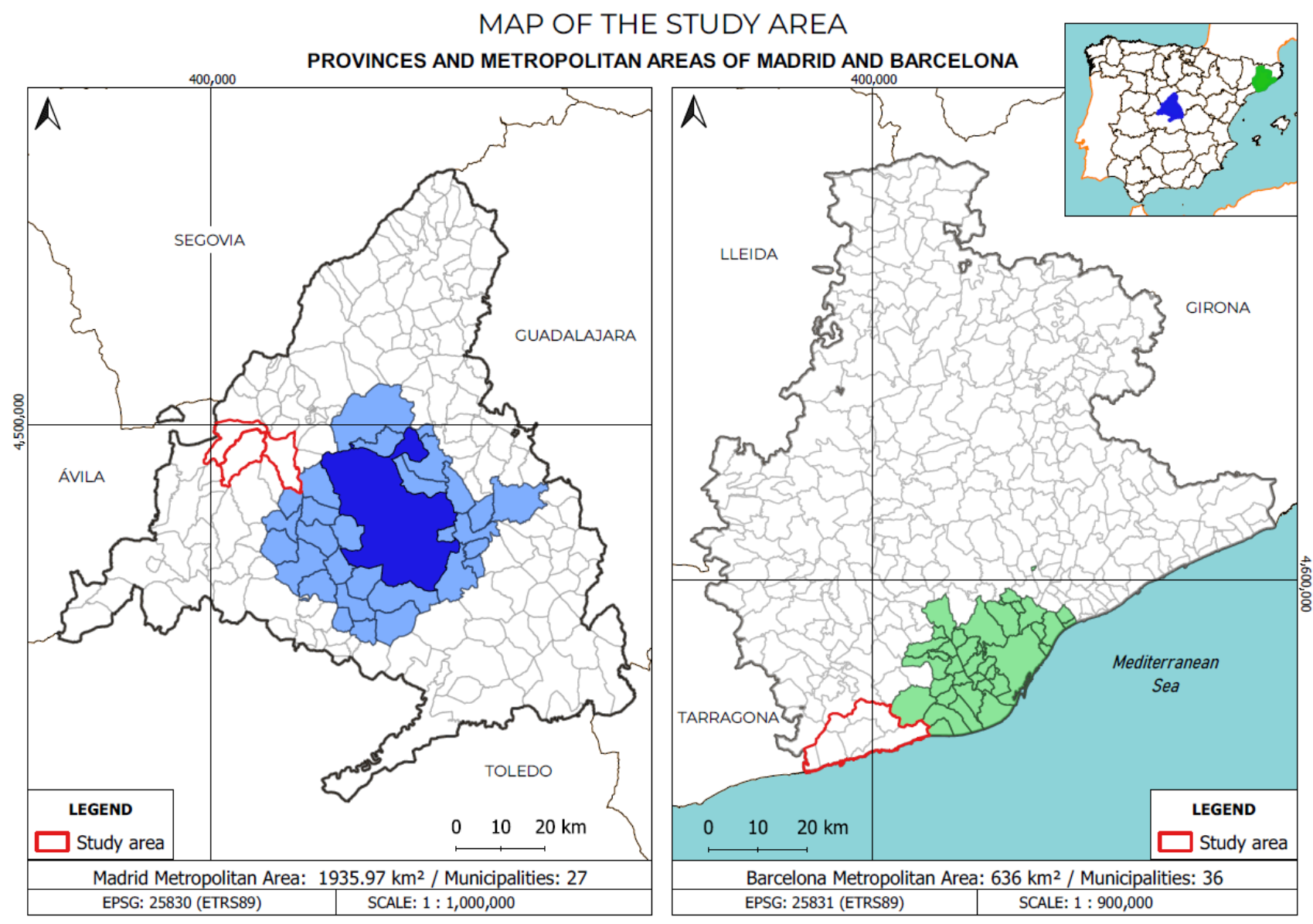

Figure 1. Location map of the metropolitan areas of Madrid and Barcelona and study areas where the methodology was tested in detail.

All these works demonstrated the usefulness of LiDAR data in the study of forest vegetation, wildfires, delimitation of WUI zones, and a highly detailed characterization of vegetation, although in small areas. The advantage of using LiDAR in terms of geographic accuracy also entails its main disadvantage: the large volume of data to be handled and the problem of its processing. When these volumes of information refer to entire regions of Europe, the use of robust databases and the automation of processes is necessary.

The use of LULC databases to delimit WUI zones in Spain has also proved to be useful [20], although Corine Land Cover (CLC) data are not the most appropriate to achieve detailed results; however, they are unquestionably useful in the creation of evolutionary maps for Europe as a whole [21], for regional realities [22], or even provincial realities [23]. In the research undertaken within the SIOSE-INNOVA project, studies were carried out on the identification of WUI zones, testing the suitability of official land-use databases (Corine Land Cover and SIOSE) in verified scenarios, such as the provinces of Navarra and Castellón [24]. The problem is the reference scale of this type of database. The Corine Land Cover (CLC) geodatabase is particularly useful for a reference scale of 1:100,000, and SIOSE for a scale of 1:25,000, but, in both cases, there is a geometrical ambiguity that makes it impossible to accurately determine the buildings exposed to risk, as information is essential for planning and preventive work.

In line with the work of this project, the Master's Thesis by León, P. [25] and Navarro Carrión, et al. [26] demonstrated the effectiveness of combining LiDAR data and LULC databases to determine the zones exposed at different scales and with the geometric accuracy needed to precisely delimit the buildings exposed at a detailed scale in the entire province of Alicante. This research began to point out solutions to the problem of Geo Small Data in order to be able to process these sources and identify the zones that are the 
subject of study within large areas (provinces or regions), with an appropriate level of precision for the local approach.

Our contribution aims to automate the working method and optimize the use of Geo Small Data techniques that allow for the massive processing of data from the combination of LiDAR point clouds, SIOSE, aerial photographs, satellite images, etc. [26]. For this purpose, the methodology was applied to more complex zones, such as Madrid or Barcelona, in order to set a model that enables the delimitation of WUI zones in any geographic context within the country, or even for Spain as a whole, and that can be easily updated as the official information sources are updated. The results of this research were verified by means of statistical sampling methods, which, along with the photointerpretation of aerial photographs and the use of the web map service (WMS) services of the SIOSE field photographs, allowed us to successfully verify the accuracy obtained in the determination of the WUI zones used as the study areas.

This research began to point to solutions to the Geo Small Data problem in order to process these sources and identify the areas under study within large areas (provinces or regions), but with an adequate level of precision for the local approach. Our work is an evolution of this methodology, which has contributed to increasing the level of automation of the processes of this work and the creation of new automated processes. Fundamentally, all the processes related to the downloading of data from the servers of the National Geographic Institute and their entry into the geodatabase of the research laboratory were automated and improved. We worked in different autonomous communities, not only in the Valencian Community, because the LiDAR information does not have the same characteristics for all the areas; although some minimums are fulfilled in all of them, there are areas, such as Madrid, where the information is denser and more detailed. This research allowed for the contemplation of all these variations in the information and definitive automation of the data download processes. In addition, techniques for checking results with aerial photographs, the systematic sampling of field areas and cross-checking with a repository of field photographs were used and improved.

However, although the obtained results were closely verified through photointerpretation and official graphic documentation, future research should continue with the formulation of qualitative verification protocols that are based in fieldwork and objectoriented remote sensing (OBIA). Therefore, the purpose of this article is limited to the automated method of delimitation of WUI zones based on official and open data, but it does not involve research on WUI in terms of landscape evolution or a qualitative assessment of different WUI typologies in metropolitan zones.

\section{Materials and Methods}

\subsection{Materials}

This research coordinated the use of large volumes of data, their analysis and their exploitation, applied to a selection of case studies, seeking simplicity in the geo-processing of information and increasing the quality and efficiency of the results. In this way, the thematic richness of the SIOSE database increases with the geometrical accuracy of LiDAR point clouds and the synergy of this complementary data approach was particularly useful in identifying the areas exposed to wildfire risk within the selected zones. According to a report by the Greenpeace organization [27], $80 \%$ of Spanish municipalities located in areas at high risk of wildfire do not have local Emergency or Self-Protection Plans, and many of them do not have all the necessary resources. This aspect gives this methodology strategic relevance in acting as basic information for the development of this type of work at a local level and helping to mitigate the loss of human life and material damage caused by these events, which are becoming more and more frequent due to the evolution of the occupation of space and the consequences of climate change.

Usually, in research works that use point clouds from ALS to detect vegetation or buildings, the points are processed to generate a raster topology, filtering LiDAR echoes, and generating a Digital Terrain Model (DTM), the corresponding digital surface models of 
vegetation and buildings (DSM), and calculation of the normalized digital surface models of vegetation and buildings (nDSM). Finally, their reclassification and polygonal vectorization are carried out, as in a previous step, to the required geoprocesses, which are used in the determination of buildings exposed to a certain distance from the forest fuel. However, the disadvantage of processing an entire province, such as Madrid or Barcelona, is that a desktop GIS tool is incapable of this work since spatial resolutions of 1 or $2 \mathrm{~m}$ generate very large models, whose polygonal vectorization is difficult, and even more so if we want to correct the resulting vector topology and perform the necessary buffering or clipping geoprocesses to determine the exposure zones.

\subsubsection{SIOSE Database}

The SIOSE database is a vector database that contains information on Land Use Land Cover at a national level [28] under the principles of the Directive INSPIRE 2007/2/CE. It is updated every 3 years and has the geodesic reference system ETRS89 (European Terrestrial Reference System 1989) and the UTM cartographic representation system with zones 28, 29,30 and 31 (UTM projection).

The technical characteristics of SIOSE are divided into geometric and semantic specifications. Among the geometric ones, we find the 1:25,000 scale, as the polygon is the only entity with its own geometry with a minimum size of between 0.5 and 2 hectares and a minimum width of $15 \mathrm{~m}$. Its semantic characteristics include the object-oriented data model (that describes the objects, attributes, etc.) [29] and relationship between polygons and thematic classes (1 polygon: $\mathrm{N}$ classes), which makes it difficult to use from a desktop GIS application. It comprises 40 simple classes, 45 predefined classes and the capacity to create infinite associations built by the users themselves from the database, which worked perfectly for this subject of study.

\subsubsection{PNOA-LiDAR Project}

The PNOA LiDAR flight covers the entire Spanish territory with point clouds with $X$, $\mathrm{Y}, \mathrm{Z}$ coordinates and other attributes, captured through ALS. To date, two coverages were conducted: the first one between 2008 and 2015, and the second one started in 2015, and it is still in execution.

The data collection process is performed through airborne LiDAR sensors. Once the point clouds are captured, they are subject to quality controls in order to automatically classify the information, thanks to the infrared values, and to colorize it with RGB based on the PNOA orthophotos. The point density is 0.5 points per $\mathrm{m}^{2}$ for Barcelona and 1 point per $\mathrm{m}^{2}$ for Madrid. The data are collected in digital files of $2 \times 2 \mathrm{~km}$ (Barcelona) and $1 \times 1 \mathrm{~km}$ (Madrid), in LAS or LAZ formats (compressed LAS format) in the ETRS89 geodesic reference system for the Spanish mainland and the Balearic Islands and REGCAN95 for the Canary Islands and the UTM projection system with the corresponding zone. The classification of LiDAR points is done according to the specification of the American Society of Photogrammetry and Remote Sensing (ASPRS).

The PNOA project has a huge field of application, which, for the purpose of the present research, lies in obtaining point clouds of buildings and vegetation through the automatic detection of terrain modifications or elements, such as buildings and fuel models.

\subsubsection{Other Sources}

Additionally, the spatial reference information from the Spanish national cartographic base (Base Cartográfica Nacional), scale 1:200,000, was used to establish provincial limits, and the national topographic map (Base Topográfica Nacional), scale 1:25,000 to obtain the cartographic grid of the study zone and the LiDAR file grid (second coverage), together with the technical specifications of the data collection. 


\subsection{Methods}

In this study, SIOSE LULC polygons were integrated with LiDAR point clouds in a PostGIS Geodatabase (PostgreSQL), and logical statements on SIOSE were used to determine the "target zones" where forest-fuel and buildings coexist or are close to each other. The resulting polygons constituted a geometrical filter to reduce the amount of LiDAR data needed for processing and, in addition, we resorted to the use of a library specializing in point cloud processing, Point Cloud Library (PCL), the creation of patches and clustering techniques. This allowed us to apply a processing model capable of being run in conventional computers in order to make it easily applicable to fire prevention in urban-wildland interfaces in any part of the Spanish territory. The reason for resorting to LiDAR data is the lack of geometric accuracy of the SIOSE LULC database, with a thematic richness that exceeds the spatial limit of its polygons and hinders the cartographic determination of the affected buildings (scale $>1: 25,000$ ).

For the detection of areas that are prone to being affected by fires in WUI zones, we decided to consider the terms intermix and interface, set by Stewart, S.I. et al. [30], but with the criteria adapted to the Spanish institutional data sources [24], which allow us to identify the SIOSE polygons that are in a situation of intermix and interface (Figure 2). The definition of intermix corresponds to polygons with a minimum of $50 \%$ of forest surface in which there are scattered residential buildings. Interface zones include polygons with dwellings, which are closer than $100 \mathrm{~m}$ to polygons with at least $75 \%$ of the forest or fuel surface. In this way, polygons with forest tree cover attributes (coniferous, hardwood deciduous, evergreen and scrub) and building coverage (isolated building, building between party walls, single-family isolated dwelling, single-family semi-detached dwelling) were selected.

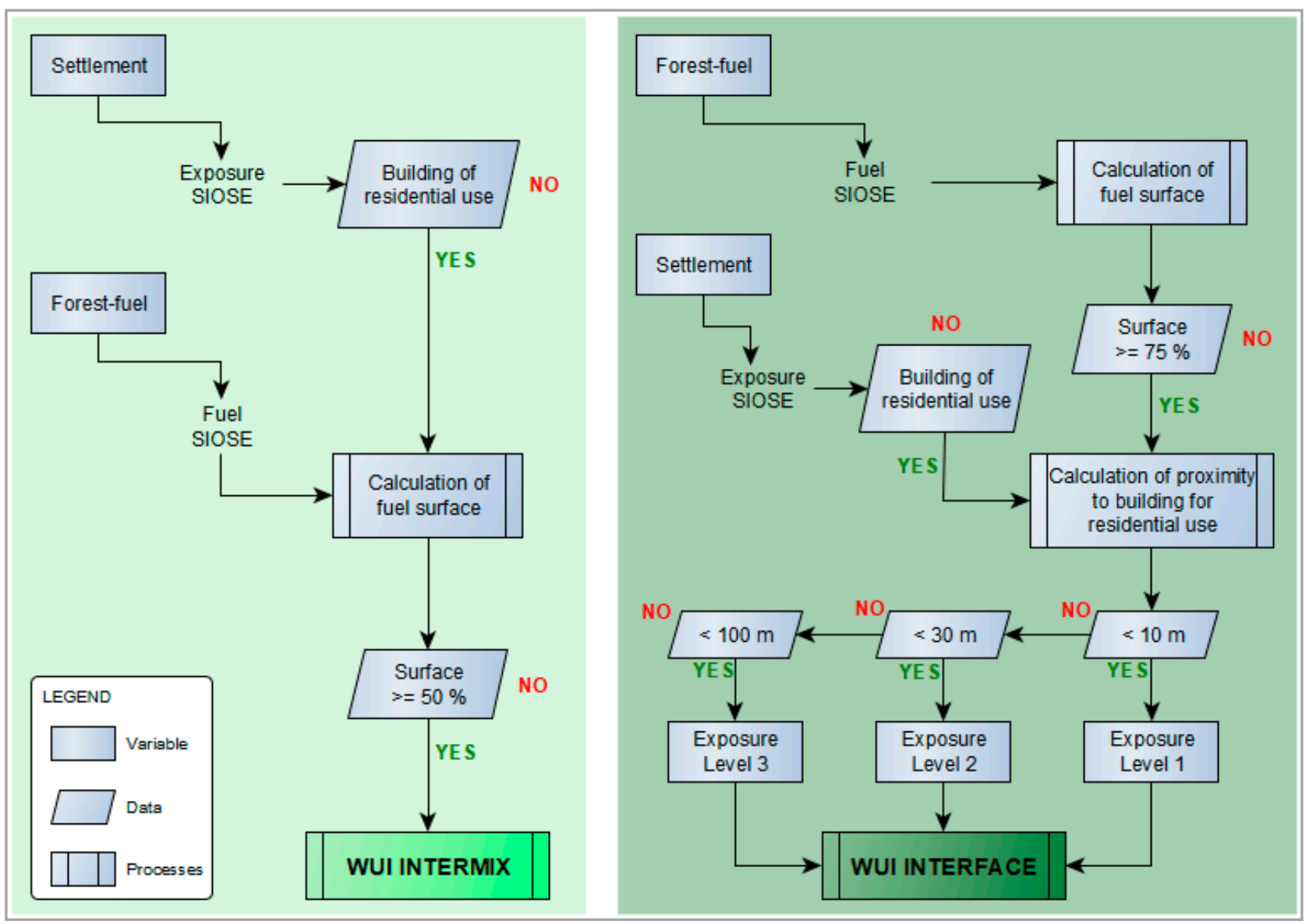

Figure 2. Theoretical procedure to calculate intermix and interface. Source: Self made from Moreno et al. [24]. 
LiDAR, on its side, provides accurate information on forest-fuel elements and their proximity to buildings, determining their exposure to fire risk [15]. However, this is particularly useful in zones of limited size since the spatial dataset to be processed for zones as large as those proposed in this research involves the problem of massive data management, as shown in Table 1: voluminous and complex information from the thematic (SIOSE) and geometric (LiDAR) perspectives. For Navarro-Carrión, J.T. et al. [26], managing this amount of information from a desktop computer with standard features is an impossible task for a desktop GIS application.

Table 1. Starting spatial data used in the investigation.

\begin{tabular}{ccc}
\hline Metropolitan Areas & Madrid & Barcelona \\
\hline SIOSE polygons & 44,000 & 73,500 \\
LiDAR points & $30,000,000,000$ & $16,000,000,000$ \\
\hline
\end{tabular}

As for LiDAR data, its download causes computational difficulty, both for its storage and for the Center of the National Geographic Institute of Spain (CNIG) state server, which only allows a limited number of files to be downloaded. In order to solve these problems, an algorithm was programmed to download geographic information in a massive, organized and systematic way. The next step was to search the values that were relevant for the research: medium and high vegetation (classes 4 y 5) and buildings (class 6), according to the classification of the American Society for Photogrammetry and Remote Sensing [31].

The use of LiDAR data through decision trees and GIS for calculating the exposure of WUI zones in Spain already proved useful at a detailed scale as in the case of Galicia [16]. In this case, the metropolitan areas of Madrid and Barcelona are exceptionally large, and it is difficult to download LiDAR data due to their massive volume. To solve this problem, a specific database was created in PostgreSQL, with PostGIS and PointCloud extensions for LiDAR data and its combination with SIOSE polygonal data in the Linux operating system. PgAdmin and QGIS were used to run additional processes and check the results that need to be monitored from a visual interface. On the other hand, for the extraction, transformation and loading of data, GDAL/OGR and PDAL libraries were used for vector and LiDAR data, respectively. For the storage of LiDAR information, patches and clustering were used to simplify the consultation tasks, as these tools allow for organization of the records by storing them by groups in a table.

The information obtained from the IGN (PNOA-LiDAR, SIOSE and complementary cartography) was processed with PostgreSQL/PostGIS, PointCloud in the NAS Server of the Geomatics laboratory of the University of Alicante and a Docker Hub Server [32]. SIOSE polygons with WUI Intermix or Interface and LiDAR point clouds relevant to us were selected to finally proceed to the necessary geoprocesses that allowed us to combine both data sources, check the differences between them and obtain an accurate delimitation of the exposed buildings. These steps are shown in the flow chart in Figure 3.

The synergy created by combining these tools prevented a computer collapse due to the large number of geometric entities to be processed, and allowed for the execution of the geoprocesses needed to meet the objectives, make complex queries and apply them to the very broad analysis areas of the study cases and in great detail. 


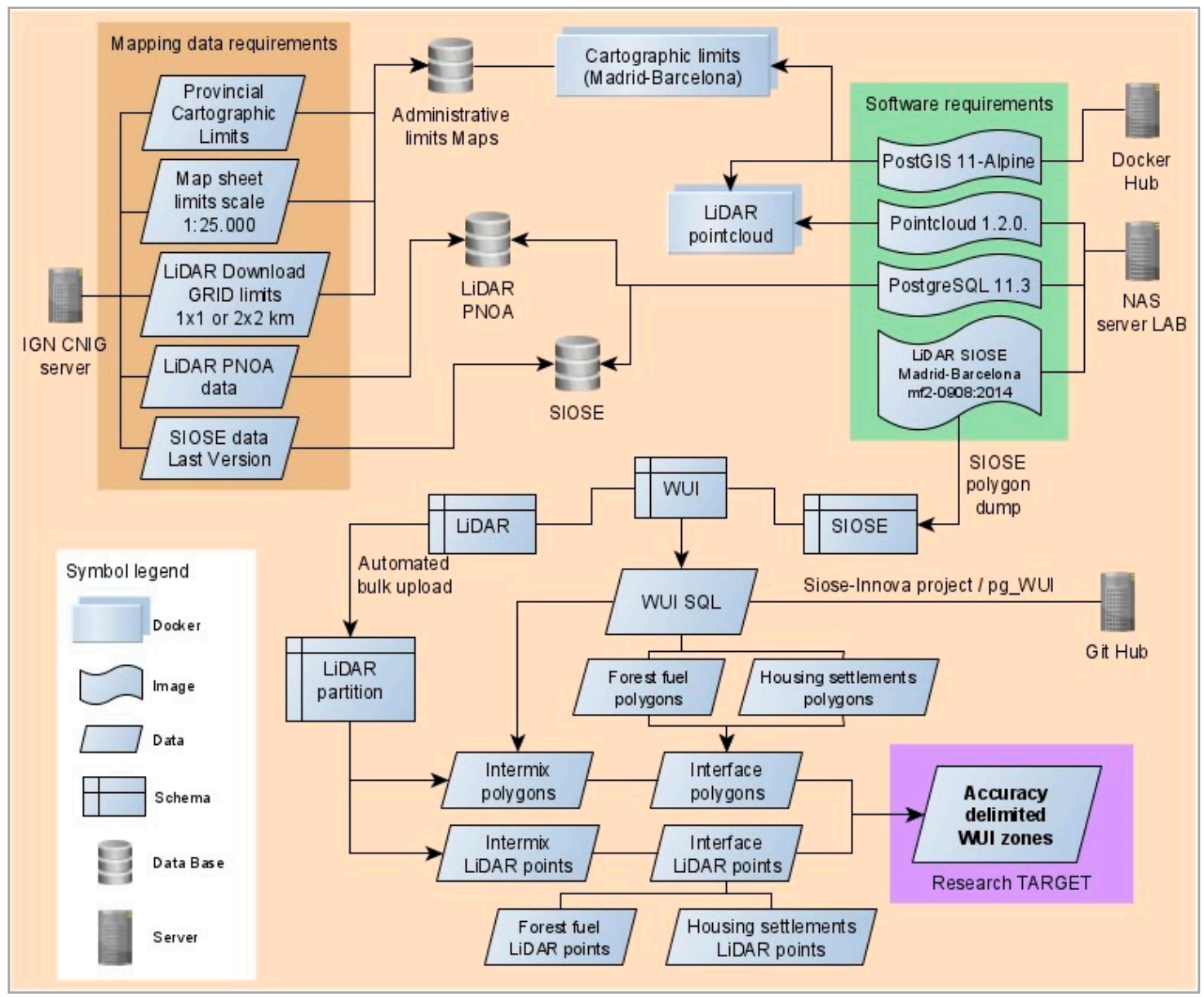

Figure 3. Theoretical procedure to calculate accuracy of delimited WUI zones.

\section{Results}

The proposed methodology was applied to the selected case studies according to the seven phases: downloading basic information, the creation and structuring of the database, intermixing and interfacing the SIOSE polygon input, the selection of LiDAR points from intermixed and interfaced polygons, the creation of LiDAR point clusters for fuel and building, the determination of intermix and interface exposure, and, finally, the research development and results.

\subsection{SIOSE-Based Determination of Exposure to Fire Risk}

The implementation of the methodology developed by Moreno, V. [24], extended in this research and applied to the provinces of Madrid and Barcelona, led to twelve relationships stored in the WUI schema of the database. The geometries generated from these relationships provide the metrics of the records computed in the processes. Figures 4 and 5 represent the entire territory, analyzed according to its type of exposure in an intermix or wildland-urban interface, obtained through the polygons of the SIOSE 2014. The polygons marked in red are the result of intermix; they are areas where residential use coexists with $50 \%$ or more of the forest mass. The polygons marked in orange are the interface ones containing residential use and located at a distance equal to or less than $100 \mathrm{~m}$ from other polygons with at least $75 \%$ or more fuel inside. 
MAP OF EXPOSURE TO THE FIRE RISK IN THE URBAN FOREST INTERFACE OF THE PROVINCE OF MADRID FROM SIOSE 2014

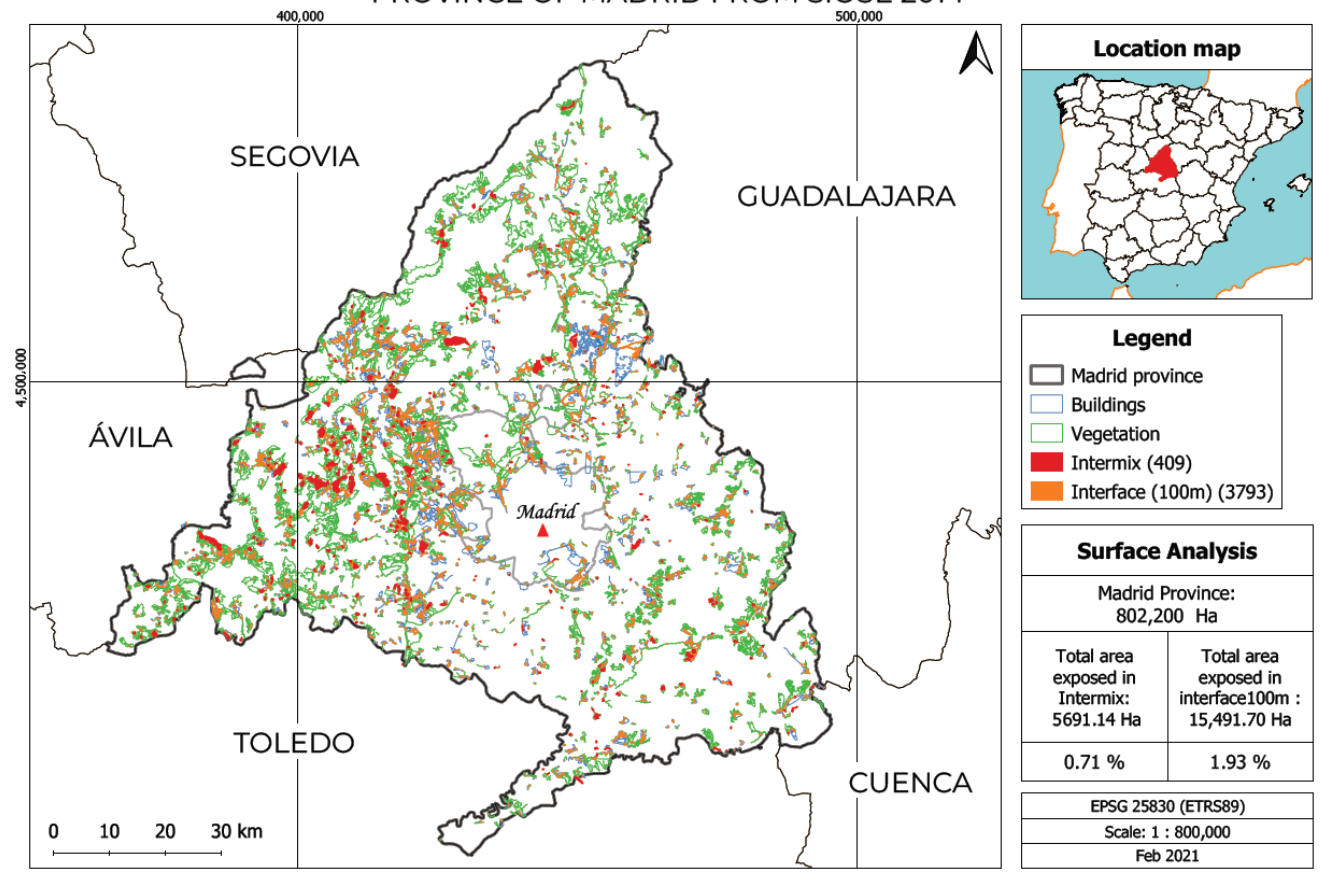

Figure 4. Exposure to wildfire risk in WUI of Madrid.

MAP OF EXPOSURE TO THE FIRE RISK IN THE URBAN FOREST INTERFACE OF THE PROVINCE OF BARCELONA FROM SIOSE 2014
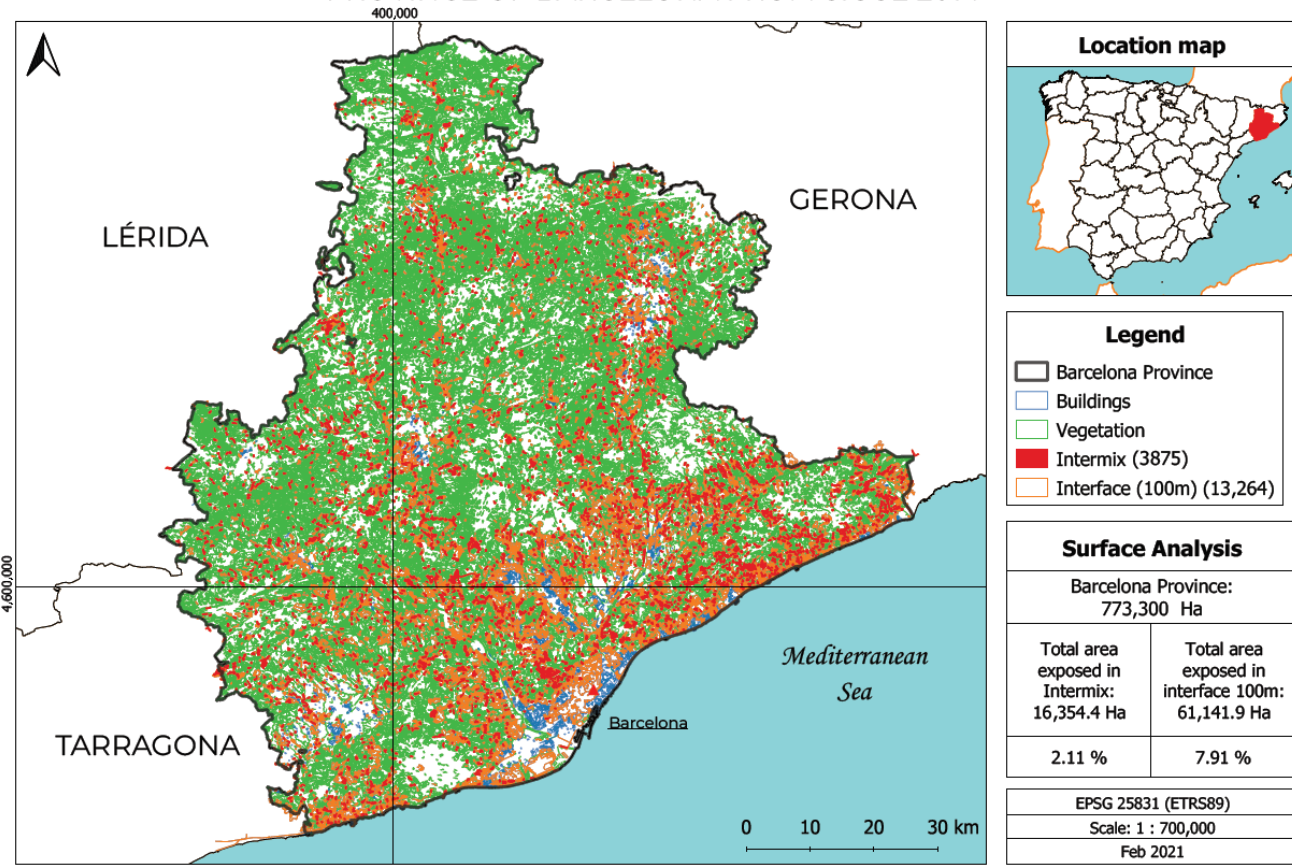

\begin{tabular}{|c|c|}
\hline \multicolumn{2}{|c|}{ Legend } \\
\hline \multicolumn{2}{|c|}{$\square$ Barcelona Province } \\
\hline \multicolumn{2}{|c|}{$\square$ Buildings } \\
\hline \multicolumn{2}{|c|}{$\square$ Vegetation } \\
\hline \multicolumn{2}{|c|}{ Intermix (3875) } \\
\hline \multicolumn{2}{|c|}{ Interface $(100 \mathrm{~m})(13,264)$} \\
\hline \multicolumn{2}{|c|}{ Surface Analysis } \\
\hline \multicolumn{2}{|c|}{$\begin{array}{c}\text { Barcelona Province: } \\
773,300 \mathrm{Ha}\end{array}$} \\
\hline $\begin{array}{l}\text { Total area } \\
\text { exposed in } \\
\text { Intermix: } \\
16,354.4 \mathrm{Ha}\end{array}$ & $\begin{array}{c}\text { Total area } \\
\text { exposed in } \\
\text { interface } 100 \mathrm{~m} \text { : } \\
61,141.9 \mathrm{Ha}\end{array}$ \\
\hline $2.11 \%$ & $7.91 \%$ \\
\hline \multicolumn{2}{|c|}{ EPSG 25831 (ETRS89) } \\
\hline \multicolumn{2}{|c|}{ Scale: $1: 700,000$} \\
\hline & \\
\hline
\end{tabular}

Figure 5. Exposure to wildfire risk in WUI of Barcelona.

The areas exposed to fire risk in the province of Madrid represent a little less than 1\% in an intermix situation and almost $2 \%$ of the territory in an interface situation according to the results obtained from SIOSE, whereas in Barcelona, they represent a little more than $2 \%$ in an intermix situation and almost $8 \%$ of the territory in an interface situation. The areas are represented at a larger scale in order to evaluate the degree of detail achieved. In Madrid, the study was conducted in the municipalities of El Escorial, Galapagar and San Lorenzo del Escorial, and in Barcelona, in the Garraf region, with the aim of representing 
urban areas with abundant forest mass. For that purpose, a sampling of the analyzed data population was carried out, which is described in the section below.

\section{Calculation of the Sample Size}

In a move to achieve methodological rigor in the different areas of the research for the development of the study phases, it was necessary to take a sample of the obtained results to identify the effectiveness of the methodology. To validate the results, we accessed the WMS of fieldwork photos taken during the development of SIOSE, and the PNOA aerial photography WMS. However, the following considerations were made to estimate the sample size: for intermix and interface polygons, the work was performed with a $10 \%$ error and $90 \%$ confidence level, considering that the sample is $50 \%$ heterogeneous.

The samples selected in municipalities of Madrid for intermix and interface consisted of 16 and 48 polygons (Figure 6a), and for Barcelona, in the Garraf region, they consisted of 42 and 60 polygons (Figure $6 \mathrm{~b}$ ). They were defined by using the random selection tools offered by QGIS, which made it possible to obtain a sample that was spatially well distributed. The selected areas show significant territorial differences in terms of their land-use distribution model, their surface and the relationship between residential zones and forest mass.

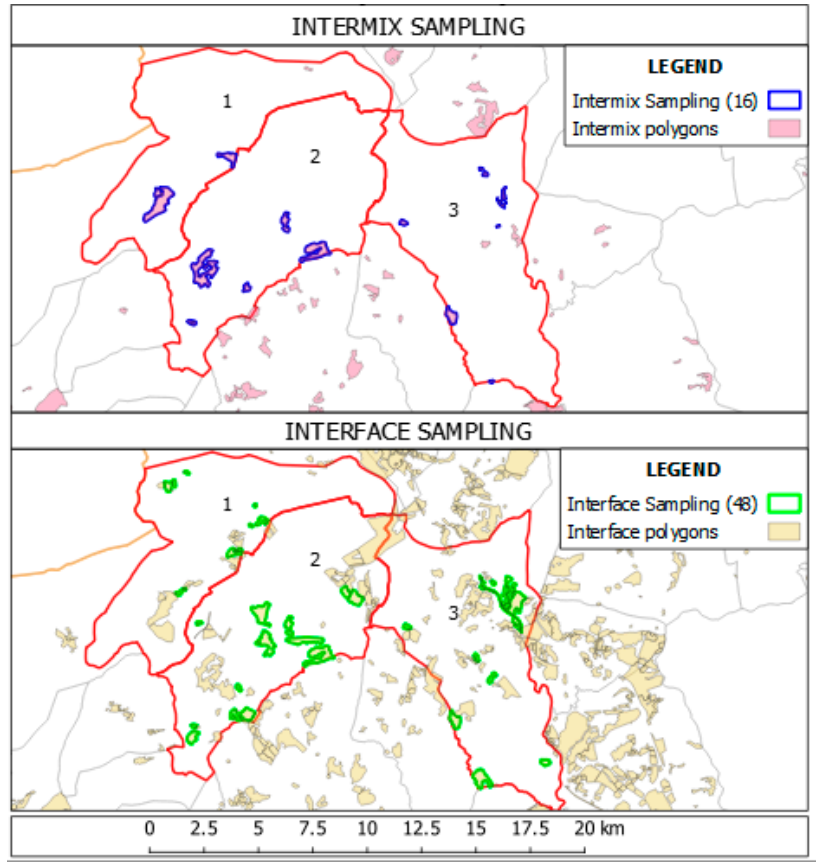

(a)

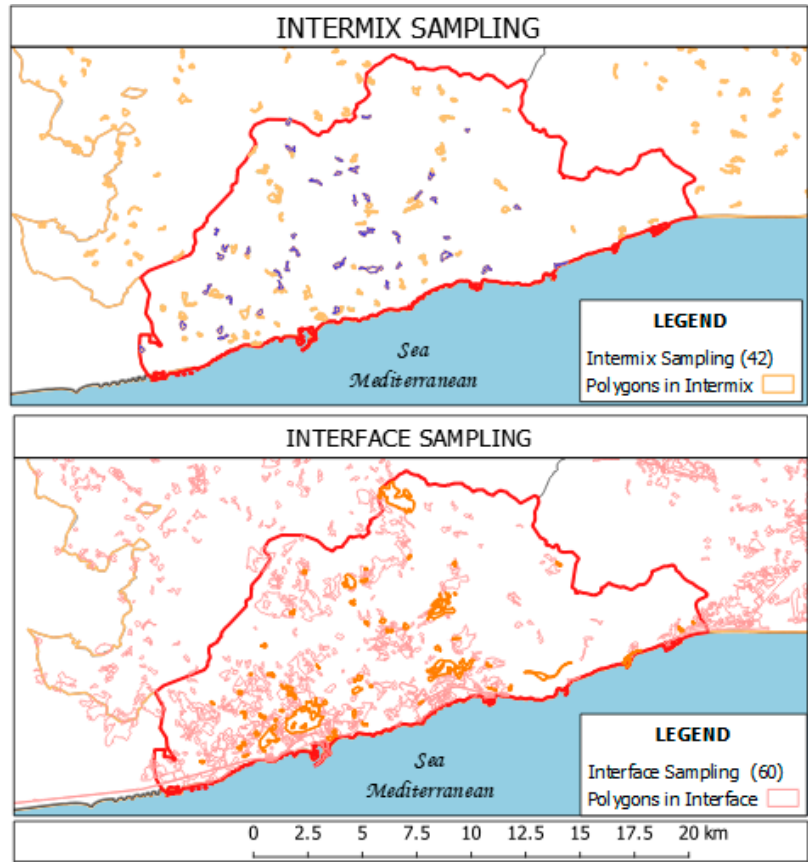

(b)

Figure 6. (a) Sample distribution of intermix polygons (SIOSE 2014) in municipalities of Madrid (1—San Lorenzo de El Escorial, 2-El Escorial, 3-Galapagar). (b) Sample distribution of intermix polygons (SIOSE 2014) in the Garraf region.

The proportion of affected areas (Table 2) in the intermix is 1.1 to 1 , while in the case of the interface, the proportion between polygons of buildings is 1.8 to 1 , which may indicate that the exposure in the selected zones of Barcelona is higher than in the selected areas in Madrid.

Table 2. Proportion of study areas.

\begin{tabular}{|c|c|c|c|c|c|c|c|}
\hline \multirow[b]{2}{*}{ Exposure } & \multicolumn{3}{|c|}{ Garraf Region } & \multicolumn{3}{|c|}{ El Escorial, S. Lorenzo del Escorial, Galapagar } & \multirow[b]{2}{*}{ Proportion } \\
\hline & Polygons & $\begin{array}{l}\text { Total Area: } \\
18,541 \mathrm{Ha}\end{array}$ & $\%$ & Polygons & $\begin{array}{l}\text { Total Area: } \\
19,047.1 \mathrm{Ha}\end{array}$ & $\%$ & \\
\hline Intermix & 110 & 439.6 & 2.4 & 20 & 401.83 & 2.1 & 1.1 \\
\hline Interface $(100 \mathrm{~m})$ & 508 & 3961.6 & 21.4 & 160 & 2323.12 & 12.2 & 1.8 \\
\hline
\end{tabular}


Based on the samples analyzed for the evaluation of the situation of intermix and interface with SIOSE, it was decided to develop sheets to assess, verify and plot the polygons concerning the sources mentioned above. In order to further refine the results, three levels of exposure (high, moderate, low) were established, as seen in Figure 7, which will be compared against the results of the operations performed with the LiDAR data. The high exposure value indicates dwellings that, in the event of a fire, would be totally compromised. The moderate value indicates dwellings that could be affected by fire to a lesser extent, due to their distance from the fuel. The low value indicates dwellings that coexist with the fuel but, due to the limited presence of forest mass or to their greater distance from it, would be affected by a fire to a lesser extent than in the previous situations.

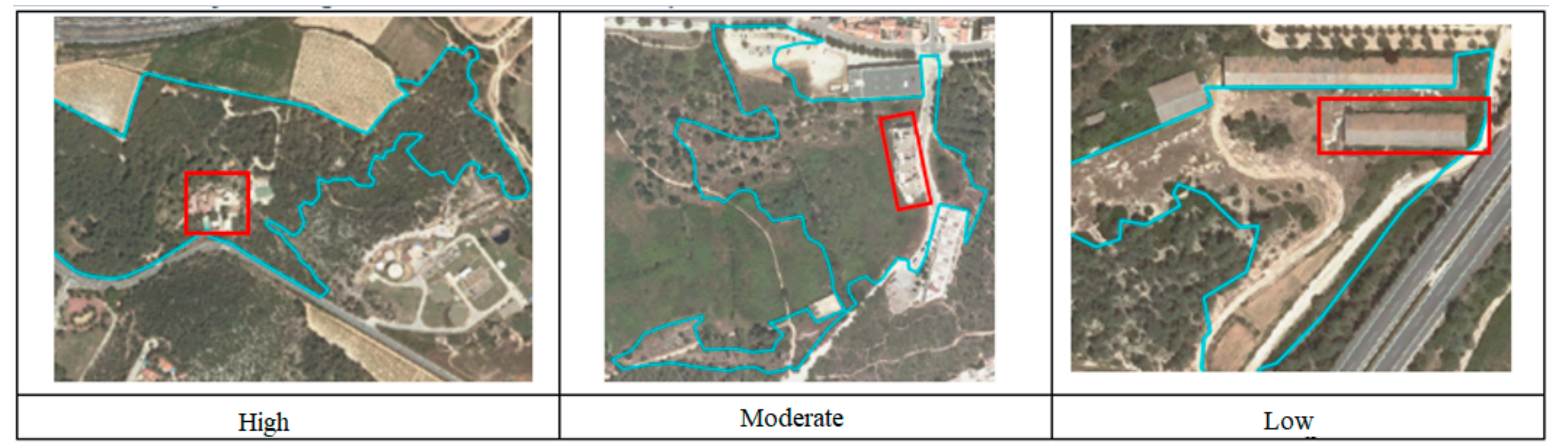

Figure 7. Generalized identification of the level of exposure.

It is worth noting that, in the intermix evaluation, the cases found in which SIOSE fails to recognize the exposure or produces "fake positives" (Table 3) are mostly due to the absence of homes within the polygons. In the case of the interface, it is more associated with the geometric ambiguity of the SIOSE information for the different coverages or uses within the same polygon with more than a $100 \mathrm{~m}$ distance from the fuel to the home for these cases. The help of the LiDAR information was essential in these cases to identify the exact location of the thematic information categories of the Land Use Land Cover surfaces (LULC) associated with each of the polygonal entities of SIOSE (association of several thematic attributes to a single geometric object).

Table 3. Exposure results in intermix and interface identified by SIOSE 2014.

\begin{tabular}{ccccc}
\hline \multirow{2}{*}{ Study Areas } & \multicolumn{2}{c}{ Intermix } & \multicolumn{2}{c}{ Interface } \\
\cline { 2 - 5 } & N\# Cases & N Cases & \% \\
\hline High & \multicolumn{3}{c}{ Municipalities of Madrid } \\
Moderate & 2 & 75 & 22 & 45.83 \\
Low & 2 & 12.5 & 12 & 25 \\
Fake positives & 0 & 12.5 & 12 & 25 \\
Total efficiency & 16 & - & 2 & - \\
& & 100 & 48 & 95.83 \\
\hline High & 25 & Garraf region of Barcelona & \\
Moderate & 8 & 59.52 & 29 & 47.54 \\
Low & 7 & 19.05 & 14 & 22.95 \\
Fake positives & 2 & 16.67 & 9 & - \\
Total efficiency & 42 & - & 61 & 85.25 \\
\hline
\end{tabular}

It can be pointed out that, for the Garraf region, where the urbanistic model is based on tourism and expansion derived from second homes, the sampled results showed that the assessment was correct for between $85 \%$ and $95 \%$ of the cases (Table 3), while for the municipalities of Madrid, it was correct for between $95 \%$ and $100 \%$ of the cases. In addition, 
there is a differentiated exposure between the study zones because in the municipalities of El Escorial, Galapagar and San Lorenzo del Escorial, there is a larger number of isolated houses that are in contact with forest and silvopastoral areas, whereas the exposure in the Garraf region mostly affects more consolidated housing areas that coexist with an abundance of fuel. However, the sampling indicates that the methodology applied is effective in identifying exposure and that it is useful for the territory under study.

\subsection{LiDAR-Based Determination of Exposure to Fire Risk}

Nonetheless, in order to further determine the level of exposure, LiDAR data were used. After obtaining the clusters of vegetation and buildings, it was decided to verify the results generated with the SIOSE database and assess how these results improve with the incorporation of LiDAR data. For this purpose, we generated sheets that show the percentages and levels of exposure determined by the sampling.

Regarding the Garraf region (Table 4), the sampling determines that the methodology is efficient for between $88.5 \%$ (interface) and $100 \%$ (intermix) of the cases, and exposure levels reclassified through the initial SIOSE identification are recognized; these results can be inferred for the rest of the region.

Table 4. Comparison of exposure between intermix and interface from SIOSE and SIOSE + LiDAR.

\begin{tabular}{|c|c|c|c|c|c|c|c|c|}
\hline & \multicolumn{4}{|c|}{ Garraf Region of Barcelona } & \multicolumn{4}{|c|}{ Municipalities of Madrid } \\
\hline & \multicolumn{2}{|c|}{ SIOSE 2014} & \multicolumn{2}{|c|}{ SIOSE 2014 + LiDAR } & \multicolumn{2}{|c|}{ SIOSE 2014} & \multicolumn{2}{|c|}{ SIOSE 2014 + LiDAR } \\
\hline & N\# Cases & $\%$ & N\# Cases & $\%$ & N\# Cases & $\%$ & N\# Cases & $\%$ \\
\hline & \multicolumn{4}{|c|}{42 samples of intermix polygons } & \multicolumn{4}{|c|}{16 samples of intermix polygons } \\
\hline High & 25 & 59.52 & 30 & 71.43 & 12 & 75 & 14 & 87.50 \\
\hline Moderate & 8 & 19.05 & 7 & 16.67 & 2 & 12.5 & 0 & 0 \\
\hline Low & 7 & 16.67 & 5 & 11.90 & 2 & 12.5 & 1 & 6.25 \\
\hline Fake positives & 2 & 4.76 & 0 & 0 & 0 & 0 & 1 & 6.25 \\
\hline \multirow[t]{2}{*}{ Total efficiency } & 42 & 95.24 & 42 & 100 & 16 & 100 & 16 & 93.75 \\
\hline & \multicolumn{4}{|c|}{61 samples of interface polygons } & \multicolumn{4}{|c|}{48 samples of interface polygons } \\
\hline High & 29 & 47.54 & 36 & 59.02 & 22 & 45.83 & 22 & 45.83 \\
\hline Moderate & 9 & 14.75 & 4 & 6.56 & 12 & 25 & 16 & 33.33 \\
\hline Low & 14 & 22.95 & 14 & 22.95 & 12 & 25 & 6 & 12.50 \\
\hline Fake positives & 9 & 14.75 & 7 & 11.48 & 2 & 4.17 & 4 & 8.33 \\
\hline Total efficiency & 61 & 85.24 & 61 & 88.53 & 48 & 95.83 & 48 & 91.66 \\
\hline
\end{tabular}

It is worth noting that the LiDAR points corresponding to homes or forest mass that were identified in the analyzed sample made it possible to adjust the exposure results and to bring them closer to the reality of the territory, which is also true in the case of polygons that, when using only the SIOSE database, showed a specific exposure level that was represented by a higher level of accuracy when complemented by the LiDAR information.

Unlike the results of Barcelona, the sampling in the municipalities of the metropolitan area of Madrid is effective for between $91.7 \%$ and almost $94 \%$ of the cases. This difference is related to the higher accuracy of the LiDAR data in this zone (Madrid $=1 \mathrm{echo} / \mathrm{sqm}$ vs. Barcelona $=0.5$ echoes $/ \mathrm{sqm}$ ), which slightly influences the quality of the results obtained.

According to the approached methodology, the zones exposed to fire risk in the wildland-urban interface within the sampling performed (Figures 8 and 9) correspond to the areas represented by the filtered clusters. 


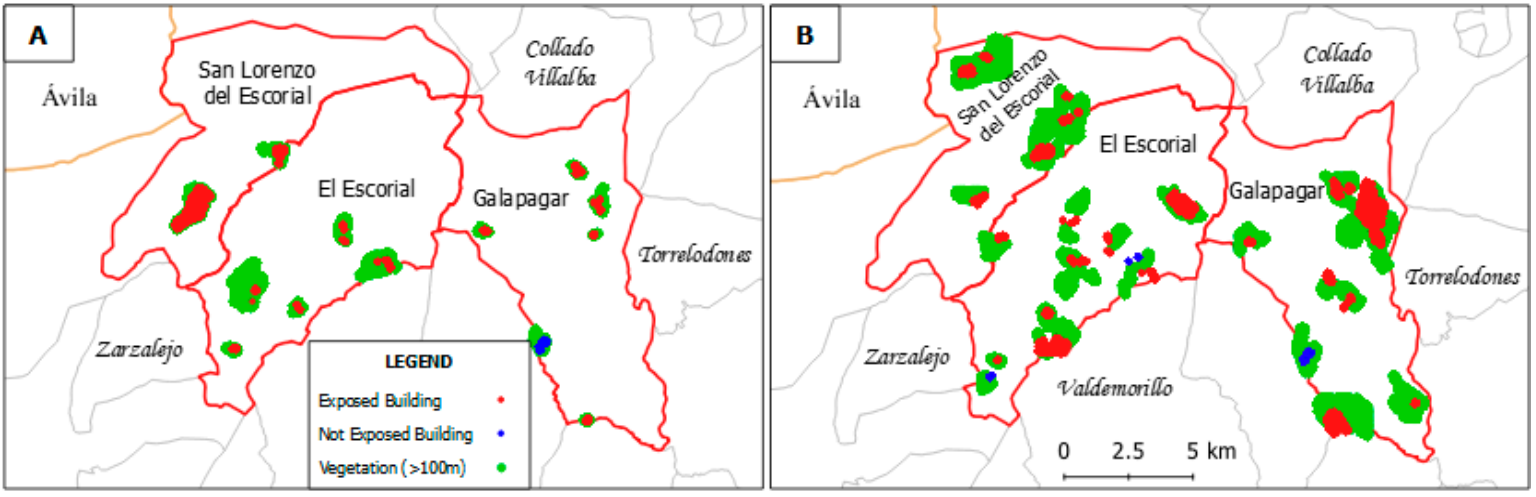

Figure 8. Clusters distribution in Garraf for analysis of intermix (A) and interface (B).
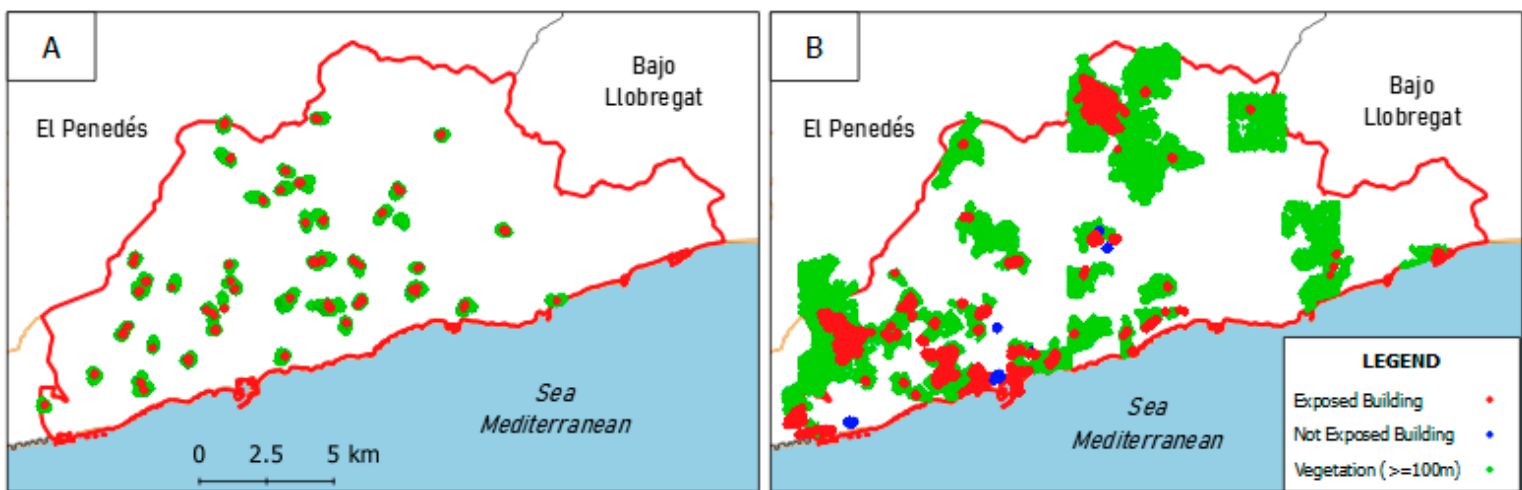

Figure 9. Clusters distribution in municipalities of Madrid for analysis of intermix (A) and interface (B).

Once the quality of the results was determined, the intermix and interface polygons identified by SIOSE were re-classified, with the positive clusters indicating that the exposed area was larger in the intermix than in the interface. These areas corresponded to the intersection between the buildings-forest mass at a distance of less than $100 \mathrm{~m}$. However, within the sample, $14 \%$ corresponded to interface polygons, which, for SIOSE, were fake positives and which, when using LiDAR, reduced this percentage to $11 \%$ since they allowed for re-classification of the exposure. It must be emphasized that it would have been impossible to reach such a degree of accuracy without the combination of both official repositories (SIOSE + LIDAR).

\section{Discussion}

This research allowed access to and the handling of information that is difficult to use due to its volume, structure, management and characteristics. A methodology was proposed to enable its use and access for users in different management levels for the development of territorial action plans, emergency plans, plans for self-protection against fire risk, and plans for a more appropriate protection of the environment in the planning of urban development projects.

The research shows that it is possible to create and manage a geodatabase containing land-use information provided by official sources (SIOSE) in combination with the voluminous LiDAR files from PNOA. Storing point clouds in patches and processing them through clusters allows for accurate identification of the WUI zones exposed to fire risk, achieving a high level of detail, applicable at different scales. The use of Geo Small Data approaches, together with the parallelization of processes, allows for high-quality results within a reasonable time.

The proposed methodology enabled the automation of a replicable process of calculation and estimation of the built-up areas exposed to fire risk, at a scale of detail appropriate for any urban planning work, estimating which areas are the most exposed to risk, and 
is applicable to accelerated urban expansion dynamics, such as the case of Barcelona or Madrid. The data sources are open, standardized and regularly updated, thus responding to a public interest, due to the impact generated by the exposure to fire risk on the safety of people and real state in the study zones. Updates allow for chronological monitoring of the phenomenon, as the official geographic information repositories are renewed.

Obtaining SIOSE polygons in intermix and interface was essential to the recovery of LiDAR points with such a high level of accuracy. To verify the results, the WMS services of the SIOSE 2014 photos and latest PNOA orthophotos were used, which allowed for a visual analysis of the study area and can always be complemented by the corresponding field work.

It should be noted that a correct analysis of cluster filtering is necessary, so that the calculation of the interaction between the variables of forest fuel-distance-residential zones provides a real estimate of the compromised areas. This situation was appropriately solved thanks to the improvements achieved in the proposed methodology in previous works $[24,26]$, which were implemented in other geographic environments (the Navarra region in the Pyrenees mountain area, and the region of Valencia in the tourist Mediterranean coast) but which share the same objective and application as this study. It is worth mentioning that the major methodological challenges to be solved refer to errors in the classification of LiDAR pulses and the difficulty of handling a point cloud as large as the ones present in this research work. The total computation time was $20 \mathrm{~h}$, and it was performed with a conventional computer with common features and free software.

The use of LiDAR data acquired by unmanned aerial vehicles (UAVs), combined with other passive and active remote sensing data, has the greatest future for fuel mapping of the wildland-urban interface (WUI), using machine-learning algorithms [33]. It is also necessary to highlight the importance of short-range LiDAR for field data collection, together with the application of qualitative and quantitative mapping methods to visualize land use in a dynamic context since it is possible to record dynamic phenomena in space, thanks to images obtained cyclically by UAVs [34]. This information would be of great value in very detailed studies for emergency management and risk prevention in those areas where the existence of fire risk exposure was previously detected. In addition, advanced topographic methods, such as the GNSS method and the object of topographic information based on low-altitude aerial imagery [35], together with field LiDAR, are decisive tools for these purposes.

However, in the case of this research, the methodological proposal was limited to the maximum exploitation of official repositories of geographic open data with national coverage for studies applied to wide regions, but with very detailed results. Perhaps it would be useful in the future to further the research in the most exposed areas detected with this methodology with the aforementioned technologies.

In the introduction, we referred to many previous studies that demonstrated the usefulness of LiDAR data in the study of forest vegetation, forest fires and delimitation of WUI zones. We also pointed out that the advantage of LiDAR accuracy also entails its main disadvantage: the large volume of data to be processed. This is an advantage or disadvantage that depends on the scale of the work and the level of precision. A single LiDAR file from the Download Center of the National Geographic Institute of Spain (CNIG) only covers an extension of $2 \times 2 \mathrm{~km}$ in Catalonia and $1 \times 1 \mathrm{~km}$ in Madrid; each of these files can contain a cloud of up to 9 million points, with more than fifteen thematic information fields associated with each of them.

Thanks to the combination of the official geographic information repositories usedSIOSE and LiDAR - in this research, it was possible to process the information from two European regions in a massive way and, at the same time, obtain a great level of detail. This went beyond the reference scale of the SIOSE database $(1: 25,000)$ and ruled out the false-positive scenarios that were classified as positive in the SIOSE polygons due to the ambiguity geometric that presented the uses of the SIOSE enclosures. On the other hand, the SIOSE data and aerial photography also made it possible to improve the LiDAR 
point cloud classification data, thereby producing a synergy between the two sources of information.

\section{Conclusions}

SIOSE has proven to be a key tool for the identification of exposed zones in the wildland-urban interface. It has an extraordinary thematic potential that is ahead of other LULC databases in terms of thematic possibilities and geometric accuracy and, if properly exploited, it allows for the identification of the phenomenon under study for the study zones in $94 \%$ of the areas exposed in the intermix situation, and between $88 \%$ and $92 \%$ for the areas in the interface situation. The decrease in the percentage between these WUI typologies relates to the geometric ambiguity of their coverage, and, therefore, other sources were used to offset this drawback through ALS active remote sensing.

LiDAR data have a high level of accuracy and detail, which enabled the identification of buildings and fuel, hence complementing the polygon information of SIOSE. The combination and complementarity of the data obtained with the proposed methodology generated a synergy capable of providing a more accurate approximation of the WUI territory exposed to fire risk within the study area. In addition, the WMS service of the cadaster of Barcelona, the PNOA orthophotographs and the field photos of the study area available through the WMS service were used in order to verify that the automated process effectively achieved the objective.

The results of this research can be applied at different scales, from a regional to a local level, and can be replicated in any area of the Spanish territory under different hazard conditions. The base information for this project comes from official repositories of the IGN National Center for Geographic Information. Although the volume and complex nature of these geographic data might limit their use to large computers, the methodology used allowed for exploitation of this information with a conventional desktop computer, creating algorithms for the identification of zones exposed to forest fuel by using free software tools and open geographic data.

Author Contributions: Corresponding author: Sabina Florina Nanu; methodology and conceptualization: José Tomás Navarro-Carrión and Alfredo Ramón-Morte; funding acquisition and project administration: Alfredo Ramón-Morte; supervision and resources: José Tomás Navarro-Carrión and Alfredo Ramón-Morte; formal analysis: José Tomás Navarro-Carrión, Sabina Florina Nanu and Andrea Zambrano-Ballesteros.; visualization: Sabina Florina Nanu and Andrea Zambrano-Ballesteros.; data curation: José Tomás Navarro-Carrión, Sabina Florina Nanu and Andrea Zambrano-Ballesteros.; software: José Tomás Navarro-Carrión; validation: José Tomás Navarro-Carrión, Sabina Florina Nanu, and Andrea Zambrano-Ballesteros.; investigation, José Tomás Navarro-Carrión, Sabina Florina Nanu, Andrea Zambrano-Ballesteros and Alfredo Ramón-Morte; writing, Sabina Florina Nanu, Andrea Zambrano-Ballesteros and Alfredo Ramón-Morte; review and editing, Sabina Florina Nanu, Andrea Zambrano-Ballesteros and Alfredo Ramón-Morte All authors have read and agreed to the published version of the manuscript.

Funding: This research was funded by and conducted within the SIOSE-INNOVA Project (CSO201679420-R AEI/FEDER/UE, Ministry of Science and Innovation, Spain) and funded by the endowment of an award for conducting research with the objectives of sustainable development (SDGs) from the General Directorate for Cooperation and Solidarity of Government of Generalitat Valenciana (Spain).

Institutional Review Board Statement: Not applicable.

Informed Consent Statement: Not applicable.

Data Availability Statement: All researchers involved approve the availability of the data in this article.

Acknowledgments: The authors are grateful to the SIOSE-INNOVA Project and the Government of Generalitat Valenciana for funding and supporting this research.

Conflicts of Interest: The authors declare no conflict of interest. 


\section{References}

1. Chuvieco, E.; Aguado, I.; Yebra, M.; Nieto, H.; Salas, J.; Martín, M.P.; Zamora, R. Development of a framework for fire risk assessment using remote sensing and geographic information system technologies. Ecol. Model. 2010, 221, 46-58. [CrossRef]

2. Las Altas Temperaturas Incrementan el Riesgo de Incendios en el Mediterráneo. Available online: http://www.fao.org/ newsroom/es/news/2007/1000640/index.html (accessed on 3 February 2021).

3. Martínez, J.; Vega-García, C.; Chuvieco, E. Human-caused wildfire risk rating for prevention planning in Spain. J. Environ. Manag. 2009, 90, 1241-1252. [CrossRef] [PubMed]

4. Moreno, M.V.; Conedera, M.; Chuvieco, E.; Pezzatti, G.B. Fire regime changes and major driving forces in Spain from 1968 to 2010. Environ. Sci. Policy 2014, 37, 11-22. [CrossRef]

5. Theobald, D.M.; Romme, W.H. Expansion of the US wildland-urban interface. Landsc. Urban Plan. 2007, 83, 340-354. [CrossRef]

6. Mell, W.E.; Manzello, S.L.; Maranghides, A.; Butry, D.; Rehm, R.G. The wildland-urban interface fire problem-current approaches and research needs. Int. J. Wildland Fire 2010, 19, 238-251. [CrossRef]

7. Pastor, E.; Muñoz, J.A.; Caballero, D.; Àgueda, A.; Dalmau, F.; Planas, E. Wildland-Urban Interface Fires in Spain: Summary of the Policy Framework and Recommendations for Improvement. Fire Technol. 2019, 56, 1831-1851. [CrossRef]

8. Badia, A.; Pallares-Barbera, M.; Valldeperas, N.; Gisbert, M. Wildfires in the wildland-urban interface in Catalonia: Vulnerability analysis based on land use and land cover change. Sci. Total Environ. 2019, 673, 184-196. [CrossRef] [PubMed]

9. Caballero, D.; Beltrán, I.; Velasco, A. Forest fires and wildland-Urban interface in Spain: Types and risk distribution. In Proceedings of the 4th International Wildland Fire Conference, Sevilla, Spain, 14-17 May 2007. Available online: http:/ /gfmc. online/doc/cd/SESIONES_TEMATICAS/ST5/Caballero_et_al_SPAIN_Tecnoma.pdf (accessed on 3 February 2021).

10. Galiana, L. The wildland-urban interface: A new risk prone area in Spain. Bull. Span. Assoc. Geogr. 2012, 58, 451-455.

11. Badia, A.; Gisbert, M. 2018 Tecnologías LIDAR como fuente de datos para la prevención de los incendios forestales en la interfaz urbana forestal. En Tecnologías de la información geográfica: Perspectivas multidisciplinares en la sociedad del conocimiento. In Proceedings of the XVIII Congreso Nacional de Tecnologías de la Información Geográfica, Valencia, Spain, 20-22 June 2018; Servicio de Publicaciones de la Universidad de Valencia: Valencia, Spain, 2018. Available online: https://ddd.uab.cat/pub/ recdoc/2018/191941/Practica1_GH_Mapificacio_variables_socioeconomiques.pdf (accessed on 3 February 2021).

12. Price, O.; Gordon, C. The potential for LiDAR technology to map fire fuel hazard over large areas of Australian forest. J. Environ. Manag. 2016, 181, 663-673. [CrossRef]

13. Denison, P.; Fryer, G.; Cova, T. Identification of firefighter safety zones using lidar. Environ. Model. Softw. 2014, 59, 91-97. [CrossRef]

14. Gonzalez-Olabarria, J.; Rodríguez, F.; Fernández, A.; Mola, B. Mapping fire risk in the Model Forest of Urbión (Spain) based on airborne LiDAR measurements. For. Ecol. Manag. 2012, 282, 149-156. [CrossRef]

15. Robles, A.; Rodriguez, M.; Alvarez, F. Characterization of wildland-urban interfaces using LiDAR data to estimate the risk of wildfire damage. Rev. Teledetección 2016, 45, 57-69. [CrossRef]

16. Fernández-Álvarez, M.; Armesto, J.; Picos, J. LiDAR-Based Wildfire Prevention in WUI: The Automatic Detection, Measurement and Evaluation of Forest Fuels. Forests 2019, 10, 148. [CrossRef]

17. Barrado-Rubio, A.M. Delimitación de la Interfaz Urbano-Forestal (IUF) y Riesgo de Incendio con Tecnologías de Información Geográfica (TIG). Master Thesis, Repositorio de la Universidad de Alicante, San Vicente del Raspeig, Spain, 2016. Available online: http:/ /hdl.handle.net/10045/58496 (accessed on 3 February 2021).

18. Barrado-Rubio, A.M. Uso de datos LIDAR para la delimitación geográfica del riesgo de incendio en zonas de interfaz urbanoforestal (IU-F) aplicado a Guisando (Ávila-España). Estud. Geográficos 2019, 80, e014. [CrossRef]

19. Vázquez-Vall, A. Las Tecnologías de Información Geográfica para la Delimitación del Riesgo de Incendio en las Zonas de Interfaz Urbana-Forestal de Náquera (Camp del Turia). Master Thesis, University of Alicante, San Vicente del Raspeig, Spain, 2017. Unpublished.

20. Herrero, G. Las Interfaces Urbano-Forestales como Territorios de Riesgo Frente a Incendios: Análisis y Caracterización Regional en España. Ph.D. Thesis, Biblioteca Universidad Autónoma de Madrid, Madrid, Spain, 2011.

21. Modugno, S.; Balzter, H.; Cole, B.; Borrelli, P. Mapping regional patterns of large forest fires in wildland-urban interface areas in Europe. J. Environ. Manag. 2016, 172, 112-126. [CrossRef] [PubMed]

22. Montiel, C.; Herrero, G. Overview of policies and practices related to fire ignitions. In Towards Integrated Fire ManagementOutcomes of the European Project Fire Paradox; Sande, J.S., Rego, F., Fernandes, P., Rigolot, E., Eds.; European Forest Institute: Porvoo, Finland, 2010; pp. 35-46. Available online: https://www.ucm.es/data/cont/docs/530-2013-10-15-efi_rr23.pdf (accessed on 5 February 2021).

23. Vilar, L.; Garrido, J.; Echavarría, P.; Martínez-Vega, F.J.; Martín, M.P. Comparative analysis of CORINE and climate change initiative land cover maps in Europe: Implications for wildfire occurrence estimation at regional and local scales. Int. J. Appl. Earth Obs. Geoinf. 2019, 78, 102-117. [CrossRef]

24. Moreno, V. La Información Geográfica Sobre Ocupación del Suelo para Analizar la Exposición al Riesgo de Incendio Forestal en Zonas Residenciales. Master Thesis, Universidad Pública de Navarra, Pamplona, Spain, 2018. Available online: https:// academica-e.unavarra.es /xmlui/bitstream/handle/2454/31201/TFM-Redaccion-COMPLETO.pdf? sequence=1\&isAllowed=y (accessed on 5 February 2021). 
25. León, P. Tecnologías de Geobigdata para la Determinación de la Exposición a Riesgo de Incendio Forestal en la Provincia de Alicante. Master Thesis, University of Alicante, San Vicente del Raspeig, Spain, 2019. Unpublished.

26. Navarro Carrión, J.T.; León-Cadena, P.; Ramon-Morte, A. Open data repositories and Geo Small Data for mapping the wildfire risk exposure in Wildland Urban Interface (WUI) in Spain: A case study in the Valencian Region. Remote Sens. Appl. Soc. Environ. 2021, 22, 100500.

27. Protege el Bosque, Protege tu Casa. Available online: https://es.greenpeace.org/es/wp-content/uploads/sites/3/2018/06/ Protege-tu-casa-protege-el-bosque.pdf (accessed on 7 January 2021).

28. IGN (2018) About SIOSE. Available online: https:/ /www.siose.es/web/guest/inicio (accessed on 3 February 2021).

29. Caballero, M.E.; Delgado, J.; Benito, M.A.; Fernández, X.; Porcuna, A. Cartografía de Ocupación del Suelo en España. Proyecto SIOSE; Catálogo general de publicaciones oficiales; Instituto Geográfico Nacional: Madrid, Spain, 2012.

30. Stewart, S.I.; Radeloff, V.C.; Hammer, R.B.; Hawbaker, T.J. Defining the wildland-urban interface. J. For. 2007, $105,201-207$.

31. Standard LIDAR Point Classes. Available online: https://www.asprs.org/wp-content/uploads/2010/12/asprs_las_format_v12. pdf (accessed on 3 February 2021).

32. Preeth, E.N.; Mulerickal, F.J.P.; Paul, B.; Sastri, Y. Evaluation of Docker containers based on hardware utilization. In Proceedings of the 2015 International Conference on Control Communication \& Computing India (ICCC), Beijing, China, 11-15 May 2015; pp. 697-700. Available online: https:/ / doi.org/10.1109/ICCC.2015.7432984 (accessed on 5 February 2021).

33. Rodríguez-Puerta, F.; Alonso Ponce, R.; Pérez-Rodríguez, F.; Águeda, B.; Martín-García, S.; Martínez-Rodrigo, R.; Lizarralde, I. Comparison of Machine Learning Algorithms for Wildland-Urban Interface Fuelbreak Planning Integrating ALS and UAV-Borne LiDAR Data and Multispectral Images. Drones 2020, 4, 21. [CrossRef]

34. Smaczyński, M.; Medyńska-Gulij, B.; Halik, Ł. The Land Use Mapping Techniques (Including the Areas Used by Pedestrians) Based on Low-Level Aerial Imagery. ISPRS Int. J. Geo-Inf. 2020, 9, 754. [CrossRef]

35. Smaczyński, M.; Horbiński, T. Creating a 3D Model of the Existing Historical Topographic Object Based on Low-Level Aerial Imagery. KN J. Cartogr. Geogr. Inf. 2021, 71, 33. [CrossRef] 